\title{
Early life history stages of goliath grouper Epinephelus itajara (Pisces: Epinephelidae) from Ten Thousand Islands, Florida
}

\author{
Monica R. Lara ${ }^{1, *}$, Jennifer Schull ${ }^{2}$, David L. Jones ${ }^{3}$, Robert Allman ${ }^{4}$ \\ ${ }^{1}$ St. Petersburg College Dept. of Natural Sciences, 2465 Drew St., Clearwater, Florida 33763, USA \\ ${ }^{2}$ NOAA Southeast Fisheries Science Center, 75 Virginia Beach Dr., Miami, Florida 33149, USA \\ ${ }^{3}$ University of Miami Cooperative Institute for Marine and Atmospheric Studies, 4600 Rickenbacker Cswy., Miami, \\ Florida 33149, USA
}

${ }^{4}$ NOAA Southeast Fisheries Science Center, 3500 Delwood Beach Road, Panama City, Florida 32408, USA

\begin{abstract}
From September through December 2001 to 2004, goliath grouper juveniles (15 to $87 \mathrm{~mm}$ standard length [SL]) were collected from tributary mouths in the Ten Thousand Islands region of southwest Florida's Gulf coast. These juveniles represent the smallest individuals of this species collected to date. These individuals were newly settled and showed only minor pigmentation. Descriptions and illustrations of juveniles between 15 and $38 \mathrm{~mm}$ SL are provided herein. Otolith analyses revealed a pelagic larval duration of 30 to $80 \mathrm{~d}$ with the potential for delayed larval metamorphosis. Based on back-calculation of daily rings, spawning generally occurred around the full moon, with settlement times irrespective of lunar phase. Length and age data provided the basis for the growth curve.
\end{abstract}

KEY WORDS: Fish · Larvae · Juvenile - Identification · Settlement · Meristics · Pigmentation · Spawning

Resale or republication not permitted without written consent of the publisher

\section{INTRODUCTION}

The goliath grouper Epinephelus itajara, formerly known as the jewfish, is a member of the family Epinephelidae and is the largest Atlantic grouper. Maximum recorded sizes for the species is $3 \mathrm{~m}$ total length (TL) and $400 \mathrm{~kg}$. Goliath grouper have maximum recorded age of $37 \mathrm{yr}$ and reach maturity at over $5 \mathrm{yr}$ and 115 to $135 \mathrm{~cm}$ TL (Robins et al. 1986, Bullock et al. 1992). The species is an important top predator and a conspicuous member of the fish fauna on coral reefs in the western, central Atlantic.

Adult goliath grouper display strong site fidelity during both reproductive and non-reproductive stages of their life histories (Smith 1976, Sadovy \& Eklund 1999, Koenig et al. 2007). As with a number of other epinephelids, goliath grouper form small spawning aggregations (10s to 100s of individuals) at predictable times and locations (Sadovy \& Eklund 1999). In south- western Florida these aggregations form in August and September on shipwrecks in 23 to $40 \mathrm{~m}$ of water (Sadovy \& Eklund 1999). Most of the large historically reported aggregations were no longer observed in the 1990s (Sadovy \& Eklund 1999), but recently at least 1 aggregation of $>50$ individuals was observed in Florida waters (NMFS 2006).

Large juveniles have been collected from inshore, shallow habitats such as seagrass beds, mangroves, bulkheads and bridges and in poorly oxygenated canals (Springer \& Woodburn 1960, Tabb \& Manning 1961, Lindall et al. 1975, Thompson \& Munro 1978, Bullock \& Smith 1991, Bullock et al. 1992, Sadovy \& Eklund 1999, Frias-Torres 2006, Koenig et al. 2007, Graham et al. 2009, this Theme Section). The goliath grouper is one of the few epinephelids that live in brackish water. Areas with extensive mangrove development seem to be particularly important nursery areas for young goliath grouper and may limit their distribution (Koenig et al. 2007). 
Larval goliath grouper are planktonic, but little is known about their abundance or manner of settlement to juvenile habitats. Virtually nothing is known about their early life history, and early post-settlement and early juvenile phases of this important reef fish are undescribed (Sadovy \& Eklund 1999, Richards et al. 2005). This study provides the first description of the early juvenile stage of the species and characterizes the smallest individuals of this species reported to date, including size at age, age at settlement, and days post-settlement. Spawning and settlement dates and the corresponding lunar phases were estimated from age data. Evidence of delayed metamorphosis in the larvae of this species is provided herein.

\section{MATERIALS AND METHODS}

Collection. To capture post-settlement goliath grouper, blue crab traps were deployed in several tributaries, man-made canals, and shallow inshore bays in the Ten Thousand Islands area of southwest Florida, USA (Fig. 1) (also see Koenig et al. 2007). Traps were baited with dead striped mullet Mugil cephalus and sampled at $7 \mathrm{~d}$ intervals, except during periods of high capture when traps were sampled daily. Traps were distributed in linear transects in shallow water $(<2 \mathrm{~m})$. Following initial trials (October 2003 to January 2004) existing traps were modified to improve capture and retention of smaller specimens and additional traps were added to the array. Modifications were made by (1) affixing $9 \mathrm{~mm}$ clam aquaculture mesh to the bottom and 3 sides of the trap, (2) placing minnow traps inside, and (3) adding mesh settlement traps externally. The latter modifications were meant to increase surface area and habitat for settlement, but this did not increase the catch of grouper specimens. The addition of aquaculture mesh to the outside of the trap, however, was critical for the retention of small individuals that previously fell through the open structure of the crab traps. Additional sampling was conducted using bottom trawls and seines over nearby seagrass beds.

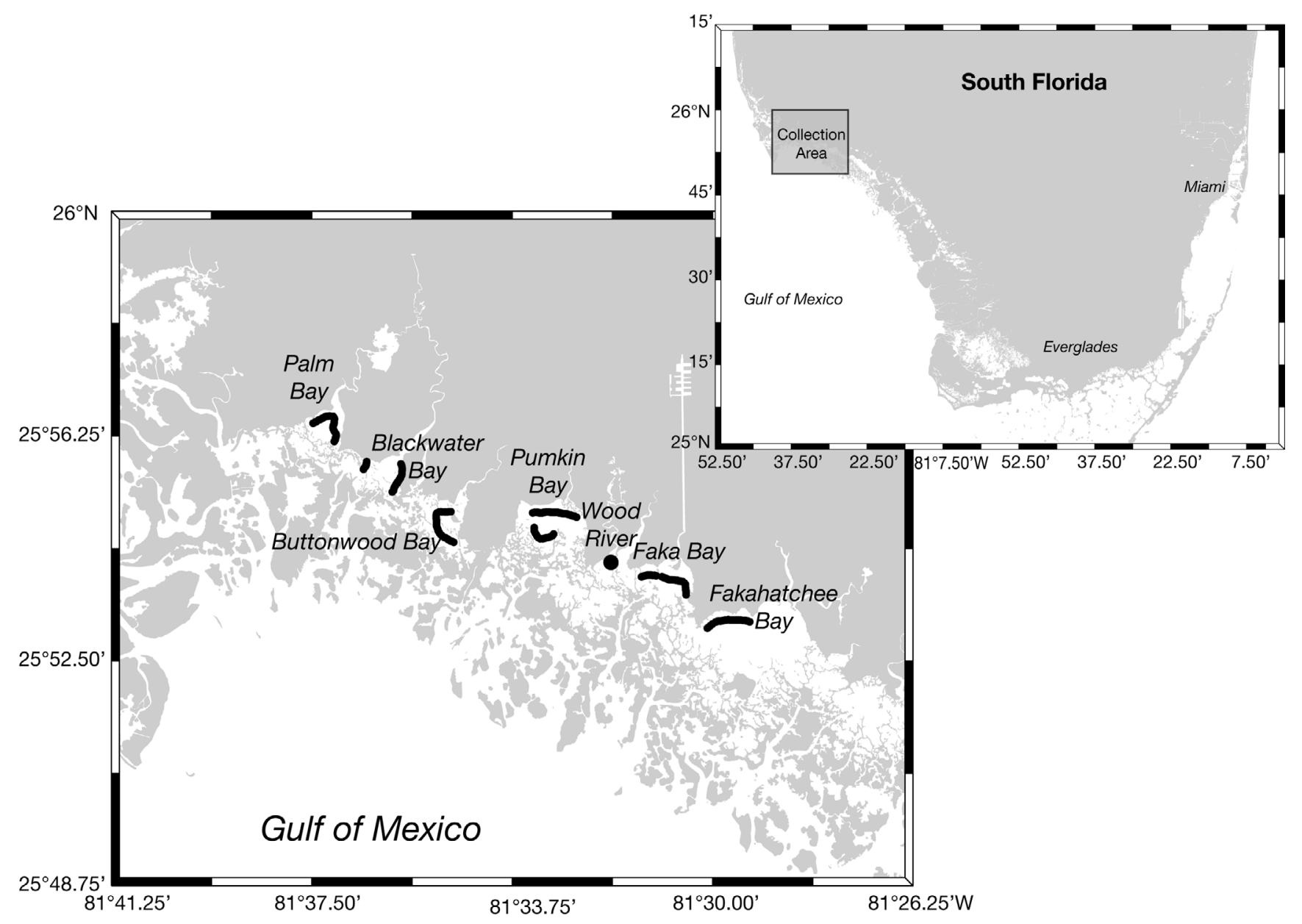

Fig. 1. Ten Thousand Islands, FL, with locations of traps that captured young juvenile goliath grouper 
Following capture, fish were either frozen or preserved in a saturated solution of butylated hydroxytoluene (BHT) in $70 \%$ EtOH within $1 \mathrm{~h}$ of capture.

Description. Specimens used for description were relaxed in a tricane methanesulfonate (MS-222)-seawater solution to extend fins and then fixed and stored in $70 \% \mathrm{EtOH}$ with BHT to maximize pigment preservation. Specimens were identified using established larval fish identification techniques, including the size series method (Powles \& Markle 1984). Meristics, pigmentation and spination are described in Table 1. All specimens were illustrated with the aid of a camera lucida by Jack Javech (NOAA Fisheries, Miami, FL) (Fig. 2).

Otolith analysis. Otoliths were extracted from specimens and cleaned using probes and a jet of $70 \% \mathrm{EtOH}$. When dry, otoliths were placed directly on a well slide and covered in medium viscosity immersion oil to improve contrast. Both sagittae and lapilli were examined and the lapilli were determined to have increments easier to distinguish from core to edge.

Images of whole otoliths were captured at $100 \times$ and $150 \times$ magnification, with software program Image J (http://rsb.info.nih.gov/ij/) used to generate intensity profiles across transects from the core to the edge. Peaks in generated profiles were counted by eye to determine the number of increments present. Increments on images were also counted by eye for cross validation and verification of counts obtained using intensity profiles. Counts were made along several axes in areas where increments were clearly legible. Both otoliths from each specimen were used when legible. Increments were assumed to be daily based on previous studies verifying the periodicity of increment formation in other species (Sadovy \& Eklund 1999, Wyanski et al. 1999, Walker \& McCormick 2004, Walker et al. 2007). Daily and sub-daily increments were distinguished using the method of Campana

Table 1. Meristics for Epinephelus itajara, reproduced from Richards et al. (2005)

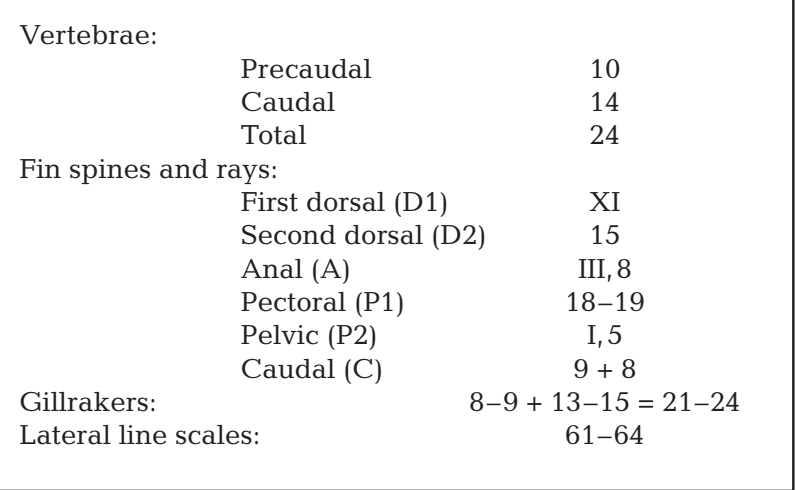

(1992). Increments were counted using a double-blind method ( 2 independent readers). A minimum of 5 trials was made for each otolith with the modal count selected as the age.

The otoliths that proved difficult to read, mainly those from larger specimens, were polished and ground on glass plates using 3600 and 6000 grit polish-
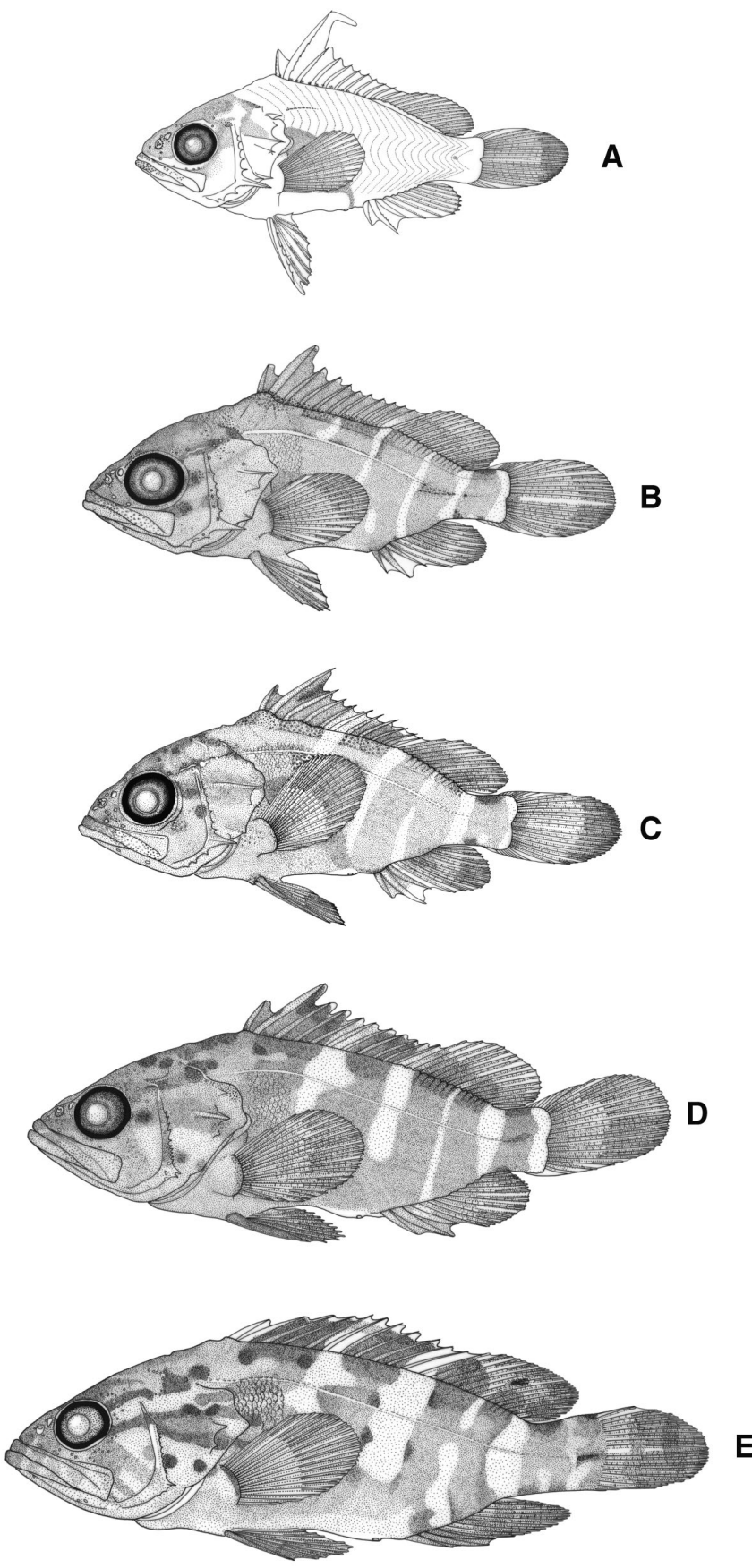

Fig. 2. Epinephelus itajara. Illustrations of juvenile goliath grouper: (A) $15 \mathrm{~mm}$ standard length (SL); (B) $16 \mathrm{~mm} \mathrm{SL}$ (C) $17 \mathrm{~mm} \mathrm{SL}$; (D) $26 \mathrm{~mm} \mathrm{SL}$; (E) $38 \mathrm{~mm} \mathrm{SL}$; illustrations by Jack Javech (NOAA Fisheries, Miami, FL). Drawings not to scale 
ing cloth (see Secor et al. 1992). After polishing, the lapillus was mounted on a microscope slide using Cytoseal $^{\circledR}$ mounting medium. Daily increments were counted under a compound microscope at 100 to $1000 \times$ magnification, with oil immersion used for the $1000 \times$ objective. Otoliths from 2 specimens were rejected because the daily increments could not be resolved.

The settlement mark in the lapillus was determined to be located where the pattern in increment widths changed markedly and a dark increment was apparent (Wellington \& Victor 1989). Increments were counted from the primordium to the settlement mark to estimate the number of days before settlement (i.e. pelagic larval duration [PLD]). Lapilli without an obvious settlement mark were excluded from analyses. Settlement dates were back-calculated from number of postsettlement increments and the date of capture, while spawning-dates were determined from the total number of increments (days) prior to capture. The resulting calendar dates were matched to the corresponding lunar phase.

\section{RESULTS}

From October 2003 to January 2004 unmodified blue crab traps captured goliath grouper ranging from 14.5 to $90 \mathrm{~mm}$ standard length (SL). All of the specimens were found among leaf litter and other detritus within the traps. Subsequent modifications to increase surface area and habitat for settlement did not increase recruitment to the traps, but did improve the retention of smaller specimens $(<10 \mathrm{~cm})$ in the traps when collecting the samples. Sampling with bottom trawls and seines over nearby sea grass beds failed to produce any specimens.

\section{Environment}

All juveniles collected were found at river mouths draining the Everglades into the Ten Thousand Islands region of Florida (Fig. 1). These areas are characterized by mud bottom with oyster shoals and shoreline densely lined with red mangrove Rhizophora mangle forest. The water was shallow $(<2 \mathrm{~m})$, turbid, and intensely stained by tannins. Salinity varied widely (A. M. Eklund and J. Schull unpubl. data).

\section{Preservation}

Frozen specimens yielded clean, whole otoliths with clearly legible daily increments, while EtOH-BHT preserved specimens retained the full range of color of the live specimens for illustrative purposes. However, the otoliths from ETOH-BHT preserved specimens were inferior to frozen specimens, were brittle and had daily increments that were difficult to resolve.

\section{Description of early juvenile stages}

Meristics taken from Richards et al. (2005) were used to distinguish this species from other epinephelid genera but not from all other Epinephelus species (Table 1). The key characteristics in the earliest juvenile goliath grouper are the spinelet features of the dorsal and anal spines, body pigmentation and gill raker counts. The larvae and early juveniles of the Epinepheline genera can be distinguished from other epinephelid genera by the presence of elongated dorsalfin spines ornamented with spinelets (Richards et al. 2005). The smallest juveniles (settlement-stage) were still identifiable using the diagnostic dorsal spine spinules characteristic of the larva of the species. However, these spines become reduced and details of spine ornamentation and shape of spinelets becomes less pronounced soon after settlement (as is the case in many species). Thus, they cannot be used to distinguish larger goliath grouper juveniles from some other juvenile epinephelids. Reliable gill raker counts can be difficult to obtain from young individuals. Therefore, juveniles can only be reliably distinguished based on meristics consistent with several Epinephelus species and the development of the pigment pattern diagnostic of E. itajara adults.

The following are characteristics diagnostic of the species arranged by size of individual in SL. The smallest specimen (14.5 mm SL, Fig. 2A) possesses very light pigment over the body and fins. The second spine of the first dorsal fin (D1) is at least $8 \times$ longer than the first and almost $2 \times$ longer than the third. The second D1 spine still retains spinules that are simple in form and directed ventrally. The preoperculum has at least 9 spines along its posterior margin, with a prominent spine at the angle.

By $16.5 \mathrm{~mm}$ SL (Fig. 2B,C), the second D1 spine is twice the length of the first spine and only slightly longer than the third. A prominent unserrated spine is present at the angle of the preoperculum, which has a darkened margin. By this size a tubular anterior nostril and fleshy lips have developed. Pigmentation occurs as round spots on the head and is in distinct round spots in an irregular blotchy pattern over the anterior portion of the body and in bars on the last third of the body. Pigment reaches onto all fins except the pectoral (P1). An un-pigmented bar is found at the base of the caudal peduncle. Four to five dark vertical bars are found on the body separated by lighter bars. This pigmentation 
is clearly consistent with patterns found in the adult, but represents an incomplete pigmentation, as pigmentation becomes more extensive in area and intensity with growth.

By 20 to $30 \mathrm{~mm}$ SL (Fig. 2D,E) 6 light vertical bars appear on the body and the dark bars previously described are more distinct. Dark blotches radiate from the eye. By $40 \mathrm{~mm}$ SL the pigment on the head appears as distinct spots. This pigmentation pattern is characteristic of the larger juveniles and adults.

\section{Age and growth}

The relationship between age (as daily otolith increments) and SL is shown in Fig. 3 ( $\mathrm{n}=45$; size range = 16 to $87 \mathrm{~mm} \mathrm{SL}$; age range $=49$ to $112 \mathrm{~d}$ ). At the lower end of the size range the number of increments was more variable than at larger sizes. Some individuals around $20 \mathrm{~mm}$ SL ( 20\%) possessed up to 60 to 70 increments (Fig. 3) and settlement marks appeared in others at over 60 to $72 \mathrm{~d}(\sim 10 \%$ or 6 of 63 samples). These data indicate that although size at settlement is not highly variable, some individuals settle at an older age (Fig. 4).

\section{Spawning and pelagic larval duration}

The lunar date of spawning was determined by back-calculation. The data presented are based on the total number of increments and assumes increment formation began on the day of hatching (within $24 \mathrm{~h}$ of spawning). Data for 45 individuals are presented in Fig. 5 and represent individuals collected in 2001, 2003

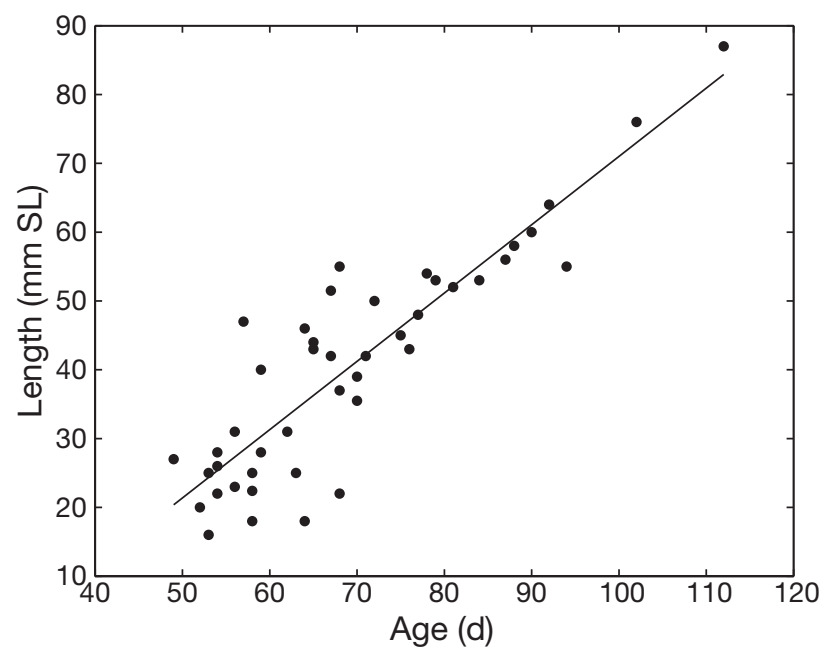

Fig. 3. Epinephelus itajara. Linear regression of length vs. age; $\mathrm{n}=45 ; \mathrm{SL}(\mathrm{mm})=$ Age $($ days $) \times 0.99-28.24 ; \mathrm{R}^{2}=0.79$, $\mathrm{p}<0.001$

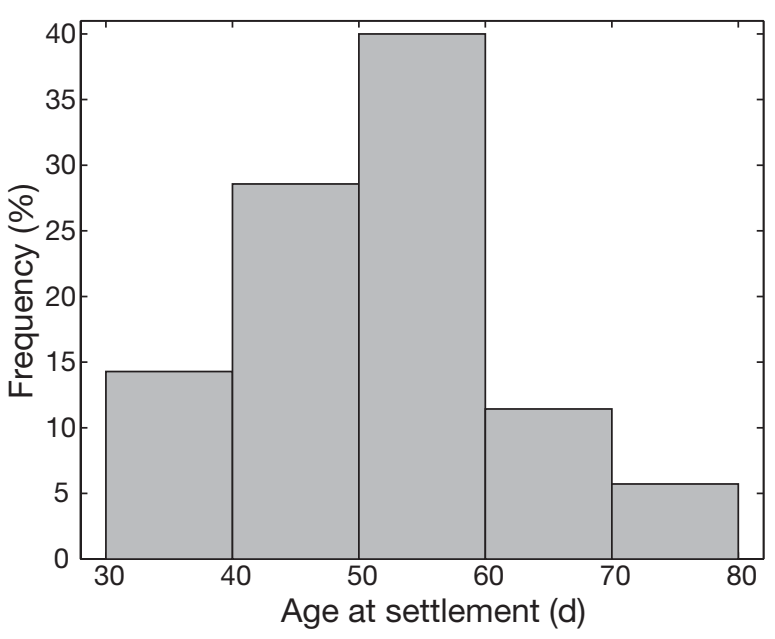

Fig. 4. Epinephelus itajara. Frequency distribution of settlement ages; $\mathrm{n}=34$

and 2004. Back-calculation of spawning dates showed that the juveniles collected were spawned in the months of July to October and that spawn dates peak around the full moon. Assuming exogenous feeding (Lindeman et al. 2000, Allman \& Grimes 2002, Philibotte 2002), the peak in spawning occurred exactly on the full moon. For this study, increment counts were not adjusted, and a difference of 2 to 3 increments is within the margin of error of the reader.

The lunar date of settlement was calculated from the day of capture and the days between the settlement mark and the edge of the otolith. Only a portion of fish $(75 \%)$ had discernible settlement checks (Fig. 6). Settlement occurred throughout the lunar cycle, with a slight peak associated with the new moon.

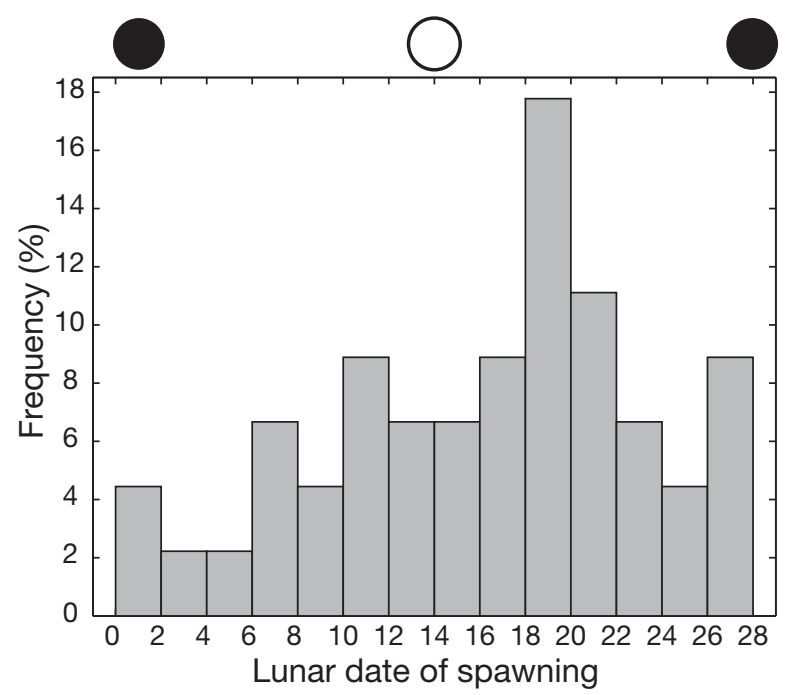

Fig. 5. Epinephelus itajara. Lunar date of spawning; $\mathrm{n}=45$; - = new moon; $\mathrm{O}=$ full moon 


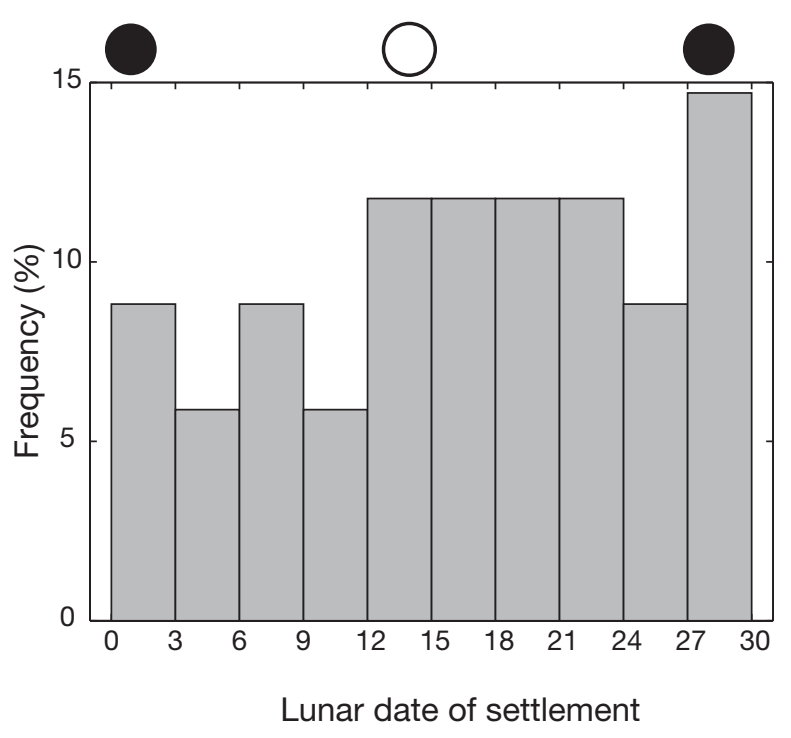

Fig. 6. Epinephelus itajara. Lunar date of settlement; $\mathrm{n}=34$; $\boldsymbol{r}=$ new moon $; \mathrm{O}=$ full moon

\section{DISCUSSION}

\section{Environment}

Goliath grouper juveniles were found over a limited area in shallow water near luxuriant mangrove-lined shores. Following deployment, traps rapidly accumulated leaf litter that closely matched the coloration and pattern of pigment of juveniles. This coloration likely assists early juveniles to avoid predation within their mangrove habitats. Although larger juveniles (101 to $1000 \mathrm{~mm}$ TL) have been captured in the lower salinity waters of the tributaries (Koenig et al. 2007), the smaller individuals described here were captured almost exclusively at tributary mouths and within the Ten Thousand Islands bays. Salinity in these areas can still vary widely ( 0 to $34.96 \mathrm{ppt}$ ), but average minimum salinities measured are generally higher than in the tributaries (A. M. Eklund and J. Schull unpubl. data) that are the source of fresh water runoff into the bays.

Subsequent to this study, on 22 October 2007, C. Ethridge and J. Coyle of the North Carolina Division of Marine Fisheries collected a $15.3 \mathrm{~mm}$ SL juvenile goliath grouper from the Pamlico Sound, NC $\left(35.59915^{\circ} \mathrm{N}, 75.4707^{\circ} \mathrm{W}\right)$, suggesting that viable larvae reach areas outside the normal range of adults.

\section{Capture methods}

Modified blue crab traps were the most effective sampling devices for capturing post-settlement goliath grouper. It is not certain whether the fish were attracted to the bait within the traps or were simply seeking shelter. It would be instructive to explore other sampling methods, such as light traps or channel nets, although high-speed currents, considerable organic debris, and tannic waters present challenges to using these methods. In addition, it is worth exploring whether the modified blue crab trap is effective in capturing goliath grouper or other species of grouper in other locations where an influx of goliath grouper larvae are suspected to occur (e.g. in Belize, R. T. Graham pers. comm.).

\section{Description}

The settlement-stage and early juveniles of this species have not been previously described. Identification was based on meristics, features of spination, and pigment in a size series of these specimens. The only previous diagnostic character for larval goliath grouper is an illustration and description of the spinelets found on the first and second spines of the D1 (Johnson \& Keener 1984). There was previously no information about early juvenile characteristics. In the case of recently settled juveniles, some useful larval characteristics still remained for species-level identification, such as the elongated dorsal spine with characteristic spinelet shape and distribution previously described (Johnson \& Keener 1984). These younger fish possessed a characteristic pigment pattern that could be consistent with several species of Epinephelus. Older juveniles having reduced spines and spinelet formation could nevertheless be linked to the other specimens in the series by meristics and the developing characteristic pigmentation shared with the largest juveniles and adults.

\section{Spawning, pelagic duration and settlement}

Otolith data from the juveniles collected in this study indicates that they were spawned in the months of July to October around the full moon. This supports the hypothesis that goliath grouper spawn around the full moon and is consistent with previous evidence that spawning occurs in southwestern Florida in these months. Although actual spawning has never been observed, aggregation formation (Sadovy \& Eklund 1999) and sound production presumed to be associated with reproduction is reported to occur around full moon (Mann et al. 2009, this Theme Section).

The source of the larvae is unknown, but may have hatched from larvae produced at presumed spawning aggregation sites in the Gulf of Mexico (Sadovy \& Eklund 1999, Eklund \& Schull 2001). Large numbers of 
adult goliath grouper are seen in the summer and early fall on wrecks in the Gulf, including the wreck of the 'Baja California' located $110 \mathrm{~km}$ from the collection site in this study. Though it is possible that spawning sites in the Gulf are the source, nearer spawning sites may exist.

The smallest specimens collected had recently settled, indicating that settlement in this species can occur at a size of 14 to $15 \mathrm{~mm} \mathrm{SL}$. Evidence of recent settlement includes the absence of a settlement mark or mark near the margin of the otolith, indicating that the individual had settled 1 or $2 \mathrm{~d}$ before capture. In addition, these settlement-stage fish retained some larval characteristics, such as limited pigmentation, elongate second dorsal- and anal-fin spines and pronounced spinules on the first few dorsal- and anal-fin spines.

The length of the larval period varied, with most settling between 40 and $60 \mathrm{~d}$ after spawning but some settling as early as $30 \mathrm{~d}$ after spawning and a few individuals apparently delaying settlement for up to $80 \mathrm{~d}$. Calculated settlement dates indicate that settlement occurs during all lunar phases. This finding is consistent with the evidence for delayed settlement in some individuals, as larvae may be settling when they reach a suitable environment regardless of the lunar phase. If the sources of these larvae are as far away as the Gulf or even the Caribbean then ability to delay settlement would lend them an advantage under variable conditions of transport over this long distance to a relatively limited nursery ground. In addition the highly turbid water may play a part in the lack of periodicity in settlement. One reason so many species of reef fish settle during the dark of the new moon is to avoid detection and possible predation by reef residents (Victor 1991). Because of the murky water where goliath grouper settle it may not be critical to settle under low light conditions, as the turbid waters would instead conceal the settlers.

Acknowledgments. We thank Dr. A. M. Eklund for first bringing our attention to these small specimens of grouper and involving us in the identification of the early stages of this important species. M. Finn was instrumental in the collection and preservation of these specimens and it was due to his expert knowledge of the species that we were able to discover any at all. We thank J. Javech for the precise, careful and beautiful illustration of the specimens. Thank you W. C. Starnes and G. Hogue of NC State Museum of Natural Sciences, and C. Ethridge and F. Rohde of NCDMF for providing the suspected specimen from Pamlico Sound. We thank Dr. M. Schmale for the use of his resources and technical assistance. We acknowledge funding from NOAA Protected Resources, NOAA Essential Fish Habitat, Marine Fisheries Initiative (MARFIN) and NOAA Coral Reef Conservation Program. The views expressed herein are those of the authors and do not necessarily reflect those of NOAA or any of its sub-agencies.

\section{LITERATURE CITED}

Allman RJ, Grimes CB (2002) Temporal and spatial dynamics of spawning, settlement, and growth of gray snapper (Lutjanus griseus) from the West Florida shelf as determined from otolith microstructures. Fish Bull (Wash DC) 100: 391-403

Bullock LH, Smith GB (1991) Seabasses (Pisces: Serranidae). Mem Hourglass Cruises 8:243

Bullock LH, Murphy MD, Godcharles MF, Mitchell ME (1992) Age, growth, and reproduction of jewfish Epinephelus itajara in the eastern Gulf of Mexico. Fish Bull (Wash DC) 90:243-249

Campana SE (1992) Measurement and interpretation of the microstructure of fish otoliths. In: Stevenson DK, Campana SE (ed) Otolith microstructure examination and analysis. Can Spec Publ Fish Aquat Sci 117:59-71

Eklund AM, Schull J (2001) A stepwise approach to investigating the movement patterns and habitat utilization of goliath grouper, Epinephelus itajara, using conventional tagging, acoustic telementry, and satellite tracking. In: Silbert JR, Nielsen JL (eds) Electronic tagging and tracking in marine fisheries. Kluwer, Dordrecht, p 189-216

$>$ Frias-Torres S (2006) Habitat use of juvenile goliath grouper Epinephelus itajara in the Florida Keys, USA. Endang Species Res 2:1-6

Graham RT, Rhodes KL, Castellanos D (2009) Characterization of the goliath grouper Epinephelus itajara fishery of southern Belize for conservation planning. Endang Species Res 7:195-204

Johnson G, Keener P (1984) Aid to identification of American grouper larvae. Bull Mar Sci 34:106-134

Koenig C, Coleman F, Eklund A, Schull J, Ueland J (2007) Mangroves as essential nursery habitat for goliath grouper (Epinephelus itijara). Bull Mar Sci 80:567-594

Lindall WN Jr, Fable WA Jr, Collins LA (1975) Additional studies of the fishes, macroinvertebrates, and hydrological conditions of upland canals in Tampa Bay. Florida Fish Bull 73:81-85

Lindeman KC, Pugliese R, Waugh GT, Ault JS (2000) Developmental patterns within a multispecies reef fishery: management applications for essential fish habitats and protected areas. Bull Mar Sci 66:929-956

> Mann DA, Locascio JV, Coleman FC, Koenig CC (2009) Goliath grouper Epinephelus itajara sound production and movement patterns on aggregation sites. Endang Species Res 7:229-236

NMFS (2006) Status report on the continental United States distinct population segment of the goliath grouper (Epinephelus itajara). January 12, 2006. National Marine Fisheries Service, St. Petersburg, FL

Philibotte J (2002) Pelagic larval duration of the Caribbean wrasse, Thalassoma bifasciatum. Biol Bull (Woods Hole) 203:245-246

Powles H, Markle DF (1984) Identification of larvae. In: Moser HG (ed) Ontogeny and systematics of fishes. Allen Press, Lawrence, KS, p 31-33

Richards WJ, Baldwin CC, Röpke A (2005) Serranide: Sea bass. In: Richards WJ (ed) Early stages of Atlantic fishes: an identification guide for the western central North Atlantic. Taylor \& Francis, Boca Raton, FL, p 1225-1331

Robins CR, Ray GC, Douglass J, Freund R (1986) A field guide to Atlantic coast fishes of North America. Houghton Mifflin, Boston, MA

Sadovy Y, Eklund AM (1999) Synopsis of biological data on the Nassau grouper, Epinephelus striatus (Bloch, 1792), and the jewfish, E. itajara (Lichtenstein, 1822). NOAA Technical Report NMFS-146 
Secor DH, Dean JM, Laban EH (1992) Otolith removal and preparation for microstructural examination. In: Stevenson DK, Campana SE (eds) Otolith microstructure examination and analysis. Can Spec Publ Fish Aquat Sci 117: $19-57$

Smith GG (1976) Ecology and distribution of eastern Gulf of Mexico reef fishes. Fla Mar Res Publ No. 19. Florida Department of Natural Resources, St. Petersburg, FL

Springer VG, Woodburn KD (1960) An ecological study of the fishes of the Tampa Bay area. Fla Board Conserv Mar Lab Prof Pap Ser 1:1-104

Tabb DC, Manning RB (1961) A checklist of the flora and fauna of northern Florida Bay and adjacent brackish waters of Florida mainland collected during the period July 1957 through September 1960. Bull Mar Sci Gulf Caribb 11:552-649

Thompson R, Munro JL (1978) Aspects of the biology and ecology of Caribbean reef fishes: Serranidae (hinds and groupers). J Fish Biol 12:115-146

Editorial responsibility: Kevin Rhodes,

Hilo, Hawaii, USA
Victor BC (1991) Settlement strategies and biogeography of reef fishes. In: Sale PF (ed) The ecology of fishes on coral reefs. Academic Press, San Diego, CA, p 231-260

Walker SPW, McCormick MI (2004) Otolith-check formation and accelerated growth associated with sex change in an annual protogynous tropical fish. Mar Ecol Prog Ser 266: 201-212

Walker SPW, Ryen CA, McCormick MI (2007) Rapid larval growth predisposes sex change and sexual size dimorphism in a protogynous hermaphrodite, Parapercis snyderi (Jordan \& Starks 1905). J Fish Biol 71:1347-1357

Wellington GM, Victor BC (1989) Planktonic larval duration of one hundred species of Pacific and Atlantic damselfishes (Pomacentridae). Mar Biol 101:557-567

Wyanski DM, White DB, Barans CA (1999) Growth, population age structure, and aspects of the reproductive biology of snowy grouper, Epinephelus niveatus, off North Carolina and South Carolina. Fish Bull (Wash DC) 98:199-218

Submitted: February 19, 2008; Accepted: March 4, 2009 Proofs received from author(s): May 4, 2009 